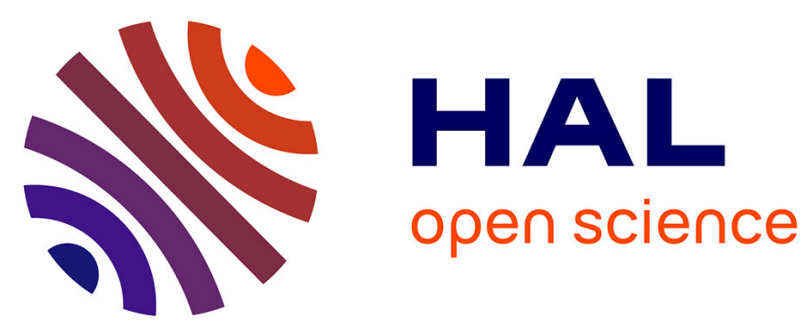

\title{
Impact of hydrolytic degradation on mechanical properties of PET - Towards an understanding of microplastics formation
}

Mael Arhant, Maelenn Le Gall, Pierre-Yves Le Gac, Peter Davies

\section{- To cite this version:}

Mael Arhant, Maelenn Le Gall, Pierre-Yves Le Gac, Peter Davies. Impact of hydrolytic degradation on mechanical properties of PET - Towards an understanding of microplastics formation. Polymer Degradation and Stability, 2019, 161, pp.175 - 182. 10.1016/j.polymdegradstab.2019.01.021 . hal03486014

\section{HAL Id: hal-03486014 https://hal.science/hal-03486014}

Submitted on 20 Dec 2021

HAL is a multi-disciplinary open access archive for the deposit and dissemination of scientific research documents, whether they are published or not. The documents may come from teaching and research institutions in France or abroad, or from public or private research centers.
L'archive ouverte pluridisciplinaire HAL, est destinée au dépôt et à la diffusion de documents scientifiques de niveau recherche, publiés ou non, émanant des établissements d'enseignement et de recherche français ou étrangers, des laboratoires publics ou privés.

\section{(ㄷ)(1) $\$$}

Distributed under a Creative Commons Attribution - NonCommerciall 4.0 International 
Version of Record: https://www.sciencedirect.com/science/article/pii/S0141391019300291

Manuscript_adcd0653701fdea64efc2d350d4ec4ef

\title{
AIMPACT OF HYDROLYTIC DEGRADATION ON MECHANICAL PROPERTIES OF PET - TOWARDS AN UNDERSTANDING OF MICROPLASTICS FORMATION
}

\author{
Mael Arhant ${ }^{1 *}$, Maelenn Le Gall ${ }^{1}$, Pierre-Yves Le Gac ${ }^{1}$, Peter Davies ${ }^{1}$ \\ ${ }^{1}$ IFREMER, Marine Structures Laboratory, \\ Centre de Bretagne, F-29280, France \\ *Corresponding author, mael.arhant@ifremer.fr
}

Keywords: Hydrolysis, Polyethylene terephthalate, Mechanical properties, Molar Mass, Embrittlement, microplastics

\begin{abstract}
Ocean pollution by microplastics, i.e. small pieces of plastic of less than $5 \mathrm{~mm}$, is one of the major concerns for the future of our planet. Secondary microplastics formation is due to fragmentation of macroplastic waste. This fragmentation can be attributed to environmental loadings such as waves, winds and tides, coupled with a change in mechanical properties of polymers induced by UV and seawater ageing. This study aims to characterize and understand changes in the mechanical behaviour of Polyethylene Terephthalate (PET) induced by hydrolysis, especially for high degradation levels. Thin films (200 microns) of PET were aged in water at temperatures from $110^{\circ} \mathrm{C}$ to $80^{\circ} \mathrm{C}$ for up to 150 days. Embrittlement occurs with chain scission during hydrolysis when molar mass of the polymer falls below $17 \mathrm{~kg} / \mathrm{mol}$. When the polymer is brittle, i.e. for high levels of degradation, the stress at break decreases linearly with the molar mass, and can be described by a simple mathematical expression.
\end{abstract}

\section{Introduction}

The presence of plastics in the oceans, from the surface to sea floor sediment, from coastal zones to open sea, has been presented in the literature since 1972 and the first papers on the subject [1-3]. The consequences of this invasion of the oceans by plastics are currently being investigated by the scientific community. Most of the questions are related to the impact of small pieces of plastics on marine life and on the food chain [4,5] and their identification in a marine environment [6-8]. When considering microplastics, defined as plastics of less than 5mm [9], two types exists. Primary microsplastics are defined as unaged plastics, such as plastic pellets, whereas secondary microsplastics are based on macroplastics such as plastic bottles or bags that are aged and then fragmented into smaller pieces. 
We will focus here on this second case, with a general objective to understand the formation of microplastics and the influence of ageing on their behaviour. From a polymer degradation point of view, the understanding of microplastic formation needs to consider new open questions related to fracture mechanisms in polymers due to extended ageing. Usually the study of polymer degradation is focused on a specific application [10] and limited to a decrease of design properties such as elongation at break for rubber [11]. Here, as there is no defined end of life for these polymers, large degradations will occur so we have to consider the impact of extensive degradation on their fracture behaviour.

The present study is focused on Polyethylene Terephthalate (PET) because this kind of polymer is widely used in industry [12], especially for plastic bottle production [13,14], and has been found as microplastics in the ocean [15]. Degradation of PET has been widely studied in the past and it was one of the first polymers studied in terms of ageing in 1959 [16]. It is well know that PET undergoes both oxidation [17,18] and hydrolysis [19], both of which lead to chain scission in the polymer. It has been chosen to focus this study mainly on hydrolysis of the polymer because the chemical reactions are known [20], the main influencing parameters have been studied, and prediction of this degradation is possible using a kinetic model [21,22]. Considering mechanical property change during degradation, it is well known that semi crystalline polymers undergo a transition from ductile behaviour (i.e. when plasticity occurs) to brittle behaviour (i.e. purely elastic behaviour) with chain scission. This transition occurs when the molar mass decreases below a critical molar mass value (usually named $\left.M_{c}^{\prime}\right)$ [23]. The $M_{c}^{\prime}$ value for PET is not clearly defined in the literature. Even if it is known that $\mathbf{M}_{\mathrm{c}}^{\prime}$ is about 5 to 20 times the $M_{e}$ value $\left(M_{e}\right.$, entanglement molar mass) a clear critical value during hydrolysis has not been determined. However, this $\mathbf{M}_{\mathrm{c}}$ value is necessary for life time prediction of polymer in industrial applications. Because here we are focussed on microplastic formation, it is necessary to consider property changes even when the molar mass is lower than $\mathbf{M}_{c}$, i.e. for high degradation. This requires first an accurate determination of $\mathbf{M}_{\mathrm{c}}$. Then, a special attention will be paid to the decrease in fracture properties for high levels of degradation which has not been documented previously, and needed some specific development in terms of testing to be able to characterize very brittle samples. Several ageing temperature (all above $\mathrm{T}_{\mathrm{g}}$ ) will be considered here in order to be able to determine a general behaviour and avoid being specific to one ageing condition. The originality of this study is to consider the mechanical behaviour of a commonly used polymer at very high degradation levels, whereas previous studies have not considered mechanical properties after embrittlement. This study does not aim to estimate an embrittlement time in natural ocean conditions (i.e. temperature below $30^{\circ} \mathrm{C}$ ) but rather to 
consider in detail the mechanical behaviour of highly degraded PET. It should be noted that extrapolation to low temperatures can only be done with an accurate value of activation energy below $\mathrm{T}_{\mathrm{g}}$, which is not available yet. In this paper we will first present the PET used, and experimental considerations such as ageing conditions and characterization. Then ageing results will be described in terms of molar mass change, crystallinity ratio and tensile behaviour during ageing in water at $105^{\circ} \mathrm{C}$. The effect of ageing temperature will then be considered. Finally, based on these results, a general interpretation of decrease in stress at break will be proposed.

\section{Materials and Methods}

\subsection{Material}

The material of interest here is a polyethylene terephthalate (PET) manufactured by extrusion and supplied by CRITT Polymeres. This PET grade (Silar 874 C80) is commonly used in plastic bottles and was received in the form of polymer films of $200 \mu \mathrm{m}$ thickness. It has a density of $1.37 \mathrm{~g} \cdot \mathrm{cm}^{-3}$ and an initial crystallinity ratio of $7 \%$. Working with polymer films rather than bulk specimens allows us to obtain a more homogeneous degradation through the thickness of the film. All specimens were recrystallized thermally before ageing at $110^{\circ} \mathrm{C}$ (the highest ageing temperature) for 30 minutes until a stable crystallinity ratio was reached $\left(\mathrm{X}_{\mathrm{c}}=33 \%\right)$. Initial molar mass and polydispersity index were measured to be $31.4 \mathrm{~kg} / \mathrm{mol}$ and 2.4 respectively.

\subsection{Method}

\subsubsection{Ageing}

Two types of ageing conditions were considered here, below and above $100^{\circ} \mathrm{C}$. Those performed below $100^{\circ} \mathrm{C}$ $\left(80^{\circ} \mathrm{C}\right.$ and $\left.90^{\circ} \mathrm{C}\right)$ were conducted in deionised water tanks at atmospheric pressure. Those performed at $100^{\circ} \mathrm{C}$, $105^{\circ} \mathrm{C}$ and $110^{\circ} \mathrm{C}$ were conducted in pressure vessels at 15 bars in order to work with deionized water in the liquid state during ageing. After each ageing condition, samples were dried in desiccators at $0 \%$ humidity and ambient temperature until the weight was stabilized. The drying process is short (because of sample thickness) and performed at low temperatures compared to those that were aged, so further hydrolysis can be neglected. Also, the dry $\mathrm{T}_{\mathrm{g}}$ was found to be $84 \pm 1^{\circ} \mathrm{C}$ and the $\mathrm{T}_{\mathrm{g}}$ at saturation, $70 \pm 1{ }^{\circ} \mathrm{C}$, which ensures that all ageing conditions are above $\mathrm{T}_{\mathrm{g}}$, even for water ageing at $80^{\circ} \mathrm{C}$. 


\subsubsection{Size exclusion chromatography (SEC)}

Molar mass was determined by SEC by the PeakExpert Company according to the Laun and al. method [24]. Samples of $10 \mathrm{mg}$ were dissolved in $4 \mathrm{~mL}$ of hexafluoroisopropanol (HFiP). The dissolution was performed for $24 \mathrm{~h}$ at room temperature. The solution was then filtered using a PTFE membrane of $0.2 \mu \mathrm{m}$ thickness. The separation was performed using a pre-column and two columns packed with $7 \mu \mathrm{m}$ PFG particles, and $1000 \AA$ and $100 \AA$ pore size, the dimension of columns was $8 \mathrm{~mm}$ ID x $300 \mathrm{~mm}$ length. The mobile phase was a mixture of $\mathrm{HFiP}+0.05 \mathrm{~mol} / \mathrm{L}$ potassium tri-fluoroacetate $(\mathrm{KTFAc})$, flow rate was $1 \mathrm{~mL} / \mathrm{min}$ and injection volume was $50 \mu \mathrm{L}$. The detection was performed using a Waters 2414 differential refractive index detector and data treated with PSS WinGPC unity v7.5 SEC software. The calibration was performed using poly(methyl methacrylate) standards supplied by PSS GmbH Mainz, Germany, with molar mass ranging between 800 and 1,600,000 g/mol and the calibration curve was adjusted with a 5th order polynomial. Calculations are conventional and average molecular weights are expressed as PMMA equivalents.

\subsubsection{Differential Scanning Calorimetry (DSC)}

The degrees of crystallinity $\mathrm{X}_{\mathrm{c}}$ were checked using DSC on Q200 equipment from TA Instruments at a heating rate of $10^{\circ} \mathrm{C} / \mathrm{min}$ from ambient temperature to $300^{\circ} \mathrm{C}$. Sample mass was around $10 \mathrm{mg}$ for all tests performed here. The degree of crystallinity is determined as follows:

$$
X_{c}=\frac{\Delta H_{f}}{\Delta H_{f}^{0}} * 100
$$

Where $\Delta \mathrm{H}_{\mathrm{f}}$ is the enthalpy of fusion of the tested polymer and $\Delta \mathrm{H}_{\mathrm{f}}{ }^{0}$ the theoretical enthalpy of fusion for a $100 \%$ crystalline material, taken equal to $118 \mathrm{~J} / \mathrm{g}$ [25]. An example of a DSC thermogram is shown in Figure 1 for the unaged PET. 


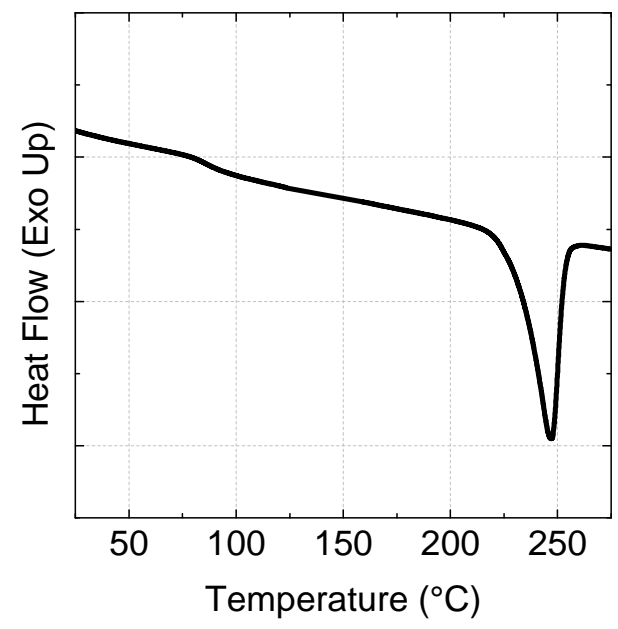

Figure 1 : DSC thermogram of the unaged PET

\subsubsection{Mechanical properties}

Tensile tests were performed using a $10 \mathrm{kN}$ capacity Instron machine with a $500 \mathrm{~N}$ load cell. Tests were performed at a crosshead speed of $1 \mathrm{~mm} / \mathrm{min}$ until failure, at $21^{\circ} \mathrm{C}$, using $\mathrm{H} 3$ dogbone specimens. The strain was measured by Digital Image Correlation (DIC) using the commercial software Aramis and a Basler camera. For each testing condition, four dry specimens were tested until failure.

\section{Results}

First, only one ageing temperature, $105^{\circ} \mathrm{C}$, will be considered, in order to describe the different phenomena that are observed and linked to water ageing. The water diffusion process was not considered here, due to the fact that the samples are thin (200 microns) and water temperature is high (up to $110^{\circ} \mathrm{C}$ ). This means that diffusivity is also high. Therefore, the time needed to reach saturation within the different specimens is very short compared to the ageing times considered in this study. To support this, in reference [26], results from water permeation data on PET can be found over a wide range of temperatures and humidity conditions. In particular, the authors state that at $70^{\circ} \mathrm{C}$ and humidity conditions between $10-30 \%$ relative humidity, the diffusion coefficient is $8.0 .10^{-}$

${ }^{12} \mathrm{~m}^{2} / \mathrm{s}$. For our study, this means that on polymer films $200 \mu \mathrm{m}$ thick, saturation will be reached after 16 minutes of water exposure. So at the higher temperatures used in the study, water sorption will be even faster. 


\subsection{Molar mass changes during ageing in water at $105^{\circ} \mathrm{C}$}

SEC results for PET aged in water at $105^{\circ} \mathrm{C}$ for several ageing durations are presented in Figure 2 . We can observe that ageing leads to a shift of the curve from higher elution volume to smaller ones without large change in the curve shape. This is clear evidence of a reduction of the molar mass during ageing, see Figure 3. Moreover, it is worth noting that the width of curves, that is related to the polydispersity index (about 2.4 here), is not affected by ageing.

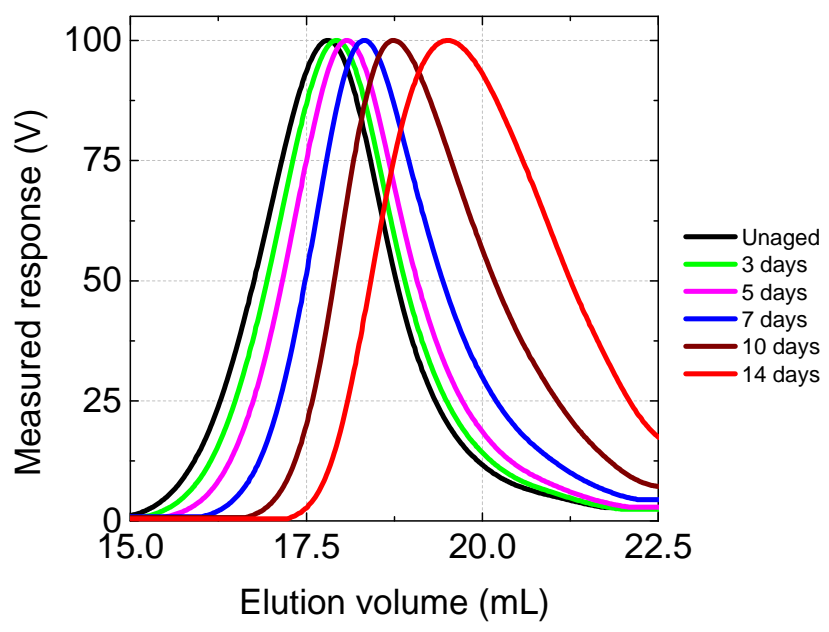

Figure 2 : SEC elution behaviour as a function of ageing

The initial molar mass $M_{n 0}$ was measured to be equal to $31.4 \mathrm{~kg} / \mathrm{mol}$. Then, it is shown in Figure 3 that the molar mass decreases throughout ageing until a final value of $3.8 \mathrm{~kg} / \mathrm{mol}$ after 14 days of ageing. This is clear evidence of a chain scission process during ageing. 


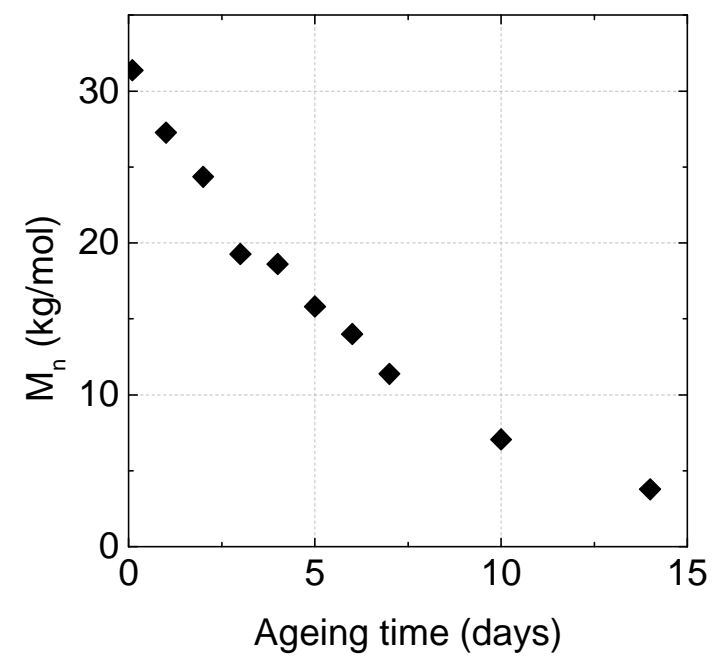

Figure 3: Changes in molar mass as a function of ageing

Based on SEC measurements, it can be concluded that an irreversible degradation occurs when PET is immersed in water at high temperatures. This degradation was expected and is attributed to the hydrolysis of the amorphous phase of the polymer that leads to chain scission, i.e. a decrease in $M_{n}$. In addition to the water ageing shown here, ageing in air and under vacuum at $110^{\circ} \mathrm{C}$ has been performed for durations up to 3 months and no evolution in the mechanical properties has been observed. These results indicated that, in this study, the main degradation mechanism is indeed hydrolysis rather than oxidation.

\subsection{Crystallinity changes during ageing in water at $105^{\circ} \mathrm{C}$}

Crystallinity is plotted as a function of ageing time in water at $105^{\circ} \mathrm{C}$ in Figure 4 . A large increase in crystallinity ratio is observed, as $\mathrm{X}_{\mathrm{c}}$ increases from $33 \%$ for unaged samples to values higher than $50 \%$ for samples aged for 14 days at $105^{\circ} \mathrm{C}$. 


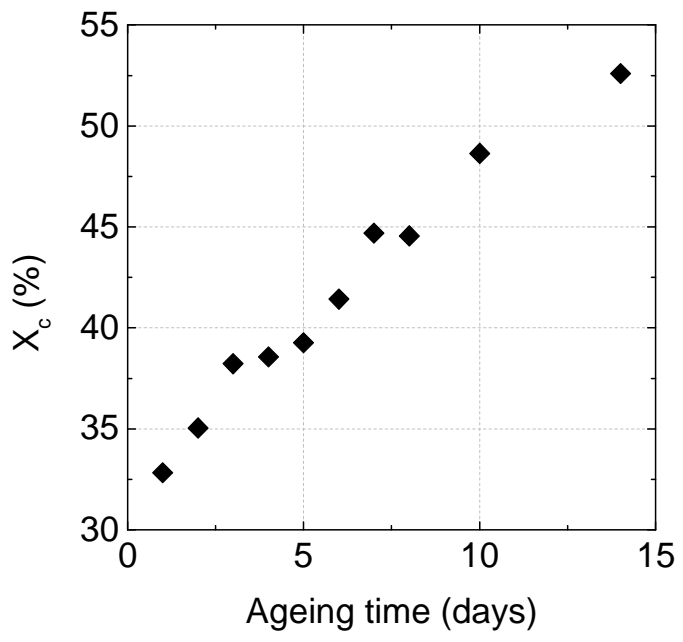

Figure 4: Changes in crystallinity as a function of water ageing

The increase in crystallinity during ageing is related to the well-known chemi-crystallization process; when chain scission occurs in the amorphous phase of a polymer the mobility of macromolecules is increased and so offers new possibilities for crystallites to be formed [27]. The chemi-crystallization process depends on the mobility of macromolecular chains meaning that this behaviour is specific to ageing above $\mathrm{Tg}$; this point is discussed in detail in the discussion section. This process has been highlighted during many previous degradation studies of polymers above $\mathrm{T}_{\mathrm{g}}[19,21]$. The relationship between chain scission and crystallinity will be considered in the discussion section, particularly for high levels of degradation.

\subsection{Mechanical Properties}

The aim of the current study is to try to identify a brittle/ductile transition as a function of ageing as well as a change in mechanical properties for high levels of degradation. To do so, specimens were tested under tension until failure as a function of ageing time. Stress-strain plots as a function of ageing are shown in Figure 5. 


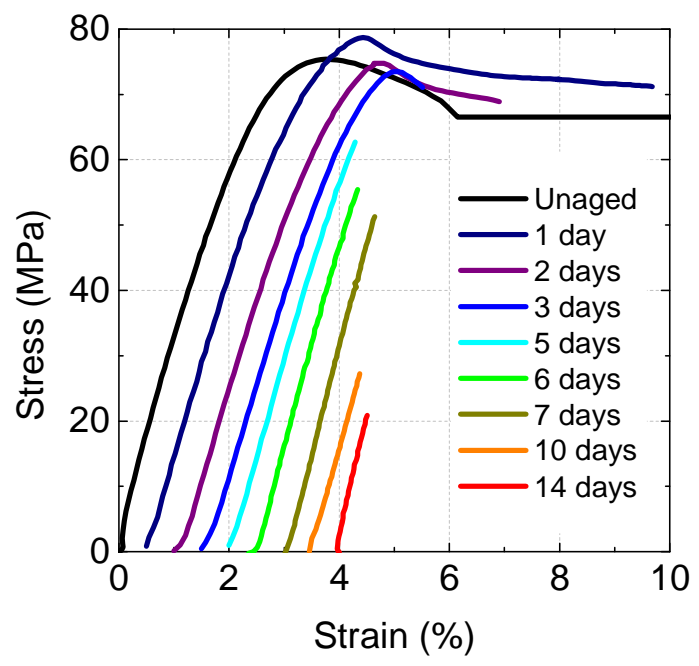

Figure 5: Change in Stress-Strain curves aged in water at $105^{\circ} \mathrm{C}$ at different ageing times

First, the unaged specimens all exhibited a ductile behaviour followed by necking at approximately $6 \%$ yield strain, which is a behaviour commonly reported for unaged PET in the literature [28]. A yield stress of approximately $75 \mathrm{MPa}$ was measured, which is close to values presented in the literature for specimens with crystallinity ratios close to $30 \%$ [28,29]. It may be noted that as stated in [29], the yield stress is not affected by the molecular weight in the range from 16.5 to $27 \mathrm{~kg} / \mathrm{mol}$, which is the case here. For these unaged specimens, tests were not performed until failure, since the neck propagated within the tabs, and did not allow a valid strain at failure to be obtained. However, it may be noted that this particular value is not the main purpose of the study, since the aim is to identify a brittle-ductile transition and not a ductile-necking transition, i.e. the conditions when microplastics can be formed.

Once the specimens were aged, even for a short period, they did not exhibit the same behaviour and no necking was observed. From 1 to 4 days of ageing, the specimens failed in a ductile manner and a yield stress was identified. On the other hand, after 5 days of ageing, all the specimens failed within the purely elastic part of the stress-strain curve, i.e. in a brittle manner. Once this brittle behaviour was identified and for ageing times longer than 5 days, the maximum stress decreases, from $63 \mathrm{MPa}$ down to $22 \mathrm{MPa}$ after 14 days of ageing, Figure 6.a, which represents a significant drop. It may be noted that testing such brittle polymer films is not an easy task and great care must be employed when performing such mechanical tests, particularly during handling of specimens. Concerning the strain at failure as a function of ageing, Figure 6.b, it also decreases, from approximately $9 \%$ after one day of ageing down to values below $1 \%$ after 14 days. 


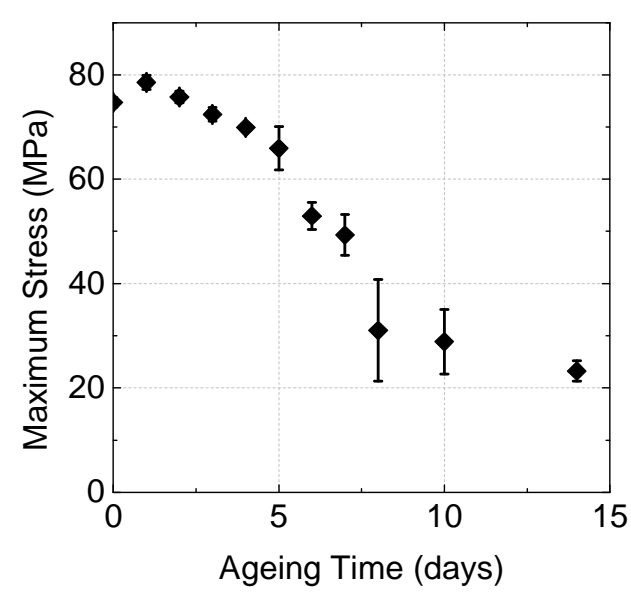

(a)

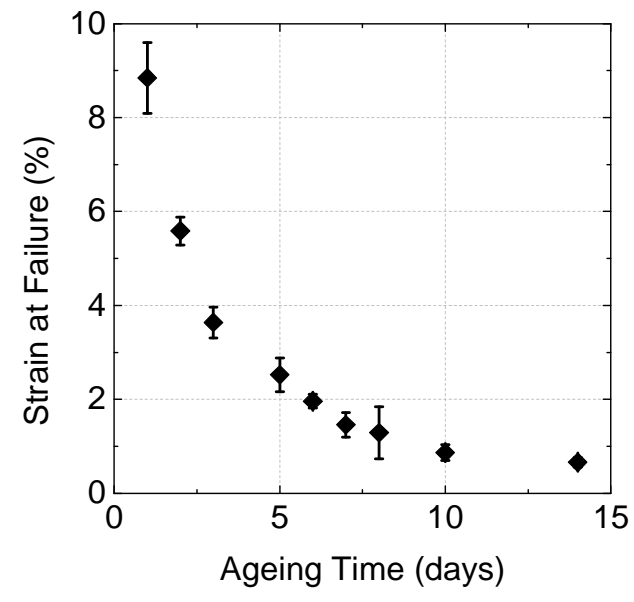

(b)

Figure 6: Changes in mechanical properties as a function of ageing at $105^{\circ} \mathrm{C}$ in water (a) Maximum stress (b)

Strain at failure

As a conclusion on the tensile behaviour, it clearly appears that the fracture of PET is strongly affected by the degradation in water at $105^{\circ} \mathrm{C}$. During hydrolysis, an embrittlement of the polymer is observed that leads to a large decrease in both strain and stress at break whereas Young's modulus remains almost constant.

Because this study aims to consider the relationship between mechanical properties and the extent of hydrolysis in a general manner ageing was also performed at other temperatures; 80, 90, 100 and $110^{\circ} \mathrm{C}$. Results are presented in the next section.

\subsection{Influence of ageing temperature}

The results presented in the previous section were obtained after ageing at $105^{\circ} \mathrm{C}$. Here, all the results obtained after ageing at $80,90,100$ and $110^{\circ} \mathrm{C}$ will be compared. For the two following figures and to simplify the presentation, the $\mathrm{x}$-axis has been plotted on a log scale in order to compare different properties at different ageing times and temperatures on the same figure. First, the changes of molar mass and crystallinity ratio at different temperatures are shown in Figure 7.a and Figure 7.b respectively. 


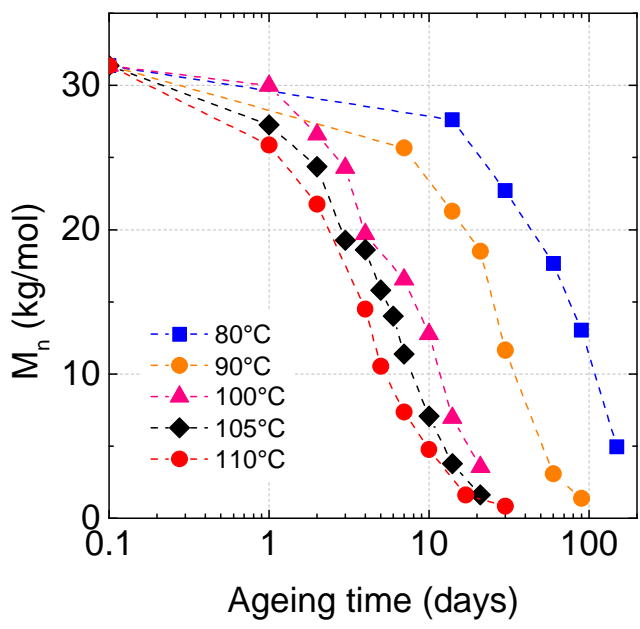

(a)

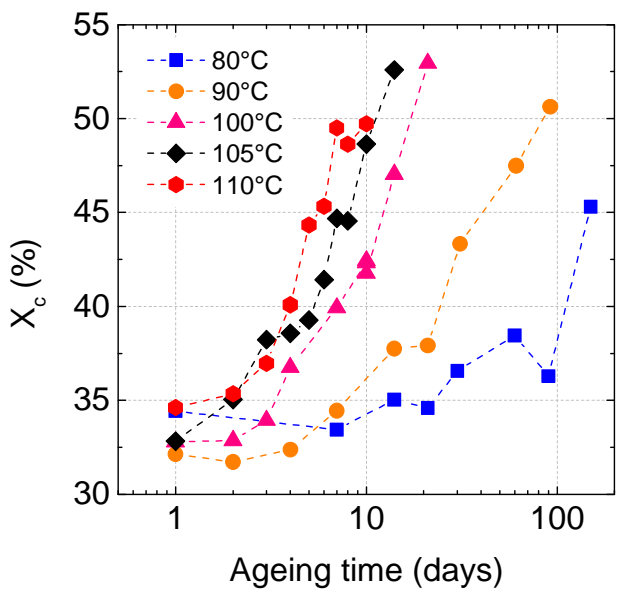

(b)

Figure 7: Changes in (a) molar mass and (b) crystallinity ratio as a function of ageing time at different temperatures

For all the ageing temperatures considered here, the same behaviour is observed; a decrease in $M_{n}$ and an increase in the crystallinity ratio. However, Figure 7.a clearly shows that the hydrolysis rate is increased with ageing temperature. This behaviour can be described using an Arrhenius law and an activation energy $E_{a}$ of 115 $\mathrm{kJ} / \mathrm{mol}$ is obtained, which is in agreement with existing literature results [16,30,31]. Activation energy is calculated with a shift factor $\mathrm{a}_{\mathrm{T}}$ using $105^{\circ} \mathrm{C}$ as the reference temperature independently for all properties considered here. Similar results are obtained concerning the crystallinity ratio, Figure 7.b, i.e. an increase in the ageing temperature results in an acceleration of the chemi-crystallization process and crystallinity ratios close to $50 \%$ are reached. It may be noted that the activation energy determined here cannot be used to extrapolate results to lower temperatures, i.e. temperatures around $20^{\circ} \mathrm{C}$. It has been stated in the literature [32] that the activation energy below $\mathrm{T}_{\mathrm{g}}$ (glassy state) is different to that above $\mathrm{T}_{\mathrm{g}}$ (rubbery state), which makes an extrapolation using an activation energy determined above $\mathrm{T}_{\mathrm{g}}$ invalid. In [32], the activation energy is approximately half of that above $\mathrm{T}_{\mathrm{g}}$ (around 1.8, these tests were performed on PET fibres at a $\mathrm{pH}$ of 14). To illustrate these results, Figure 8 shows an extrapolation using an Arrhenius approach at $20^{\circ} \mathrm{C}$ using both $\mathrm{E}_{\mathrm{a}}$ values. First, we consider an extrapolation at $20^{\circ} \mathrm{C}$ using the activation energy determined above $\mathrm{T}_{\mathrm{g}}$ and second using the same activation energy divided by 1.8 because the activation energy is lower below $\mathrm{T}_{\mathrm{g}}$. 


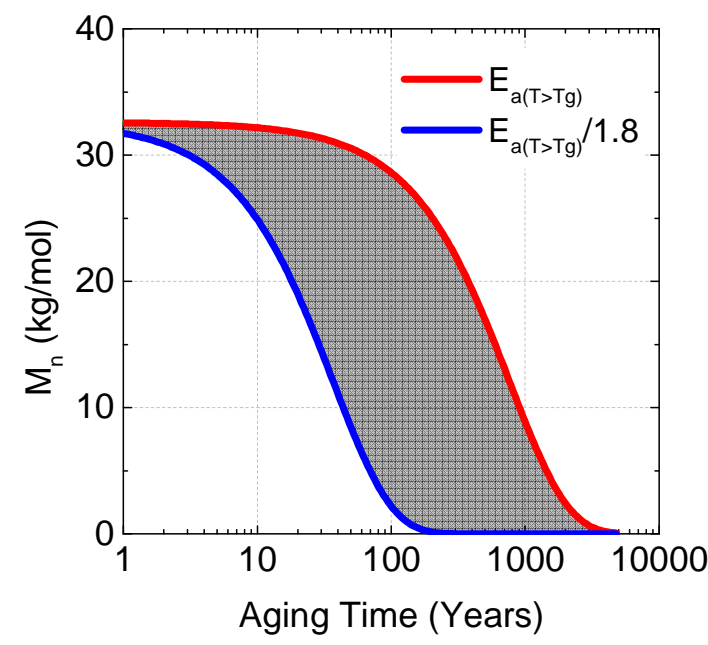

Figure 8: Extrapolation at $20^{\circ} \mathrm{C}$ (i.e. below $\mathrm{T}_{\mathrm{g}}$ ) in water of $\mathrm{M}_{\mathrm{n}}$ decrease as a function of aging time in two cases. First using an activation energy determined above $\mathrm{T}_{\mathrm{g}}$ (rubbery state) in this study and secondly considering that the activation energy is different in the glassy state (1.8 ratio [32]).

Results in Figure 8 show that depending on the activation energy used in the calculation, degradation times are quite different. While considering an activation energy equal to that determined above $\mathrm{T}_{\mathrm{g}}$, embrittlement (see later in the paper for its definition) would occur after 500 years of immersion whereas using an activation energy in the glassy state, it will take approximately 20 years. These two approaches show that the time to embrittlement is clearly overestimated when using an activation energy determined in the rubbery state to extrapolate to immersion temperatures below $\mathrm{T}_{\mathrm{g}}$. Therefore, aging tests below $\mathrm{T}_{\mathrm{g}}$ are necessary when an accurate extrapolation is needed, but this type of study takes time, as shown in Figure 8."

Then, the maximum stress values obtained from all the tests performed in this study are compared in Figure 9, again using the $\log$ scale $\mathrm{x}$-axis at the different temperatures of interest. The maximum stress was preferred as a criterion to follow degradation rather than the strain at failure, as it was considered to be the most pertinent parameter here. 


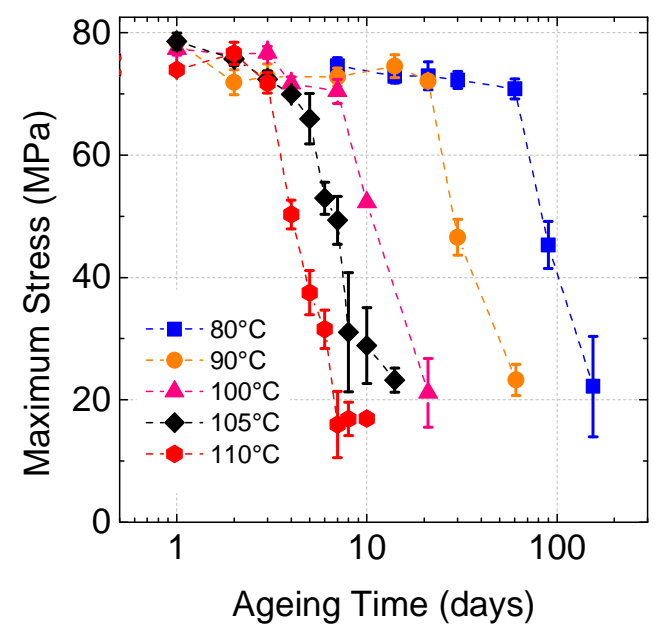

Figure 9: Changes in maximum stress as a function of ageing time at different temperatures

Results show that for each temperature studied here, the same behaviour is observed. The maximum stress drops slightly initially, and the embrittlement of the polymer then leads to a large reduction. A critical time can be identified at each ageing temperature when the maximum stress drops significantly, and this corresponds to brittle failures. It may be noted that this embrittlement of PET during hydrolysis has already been observed by Pickett and Coyle [33] at different temperatures and humidity conditions using a bending test. However, SEC measurements were not performed and no tensile mechanical criterion was proposed. The aim of this study is therefore to extend that work, as the aim is to characterize the mechanical properties of PET after extensive degradation and embrittlement, and to relate properties to SEC results.

\section{Discussion}

This section will discuss the results presented previously in order to understand the mechanical property loss during PET hydrolysis. First, the chemi-crystallization process will be considered and then focus will be placed on the establishment of a relationship between mechanical behaviour and the hydrolysis process.

\subsection{Chemi-crystallization}

In section 3.1, it was shown that the predominant degradation mechanism observed here is hydrolysis, which leads to a significant drop in the molar mass as a function of ageing. This induces a chemi-crystallization process 
which has an effect on the crystallinity ratio that increases during ageing. This change is now plotted as a function of molar mass for all the ageing temperatures considered here, Figure 10.

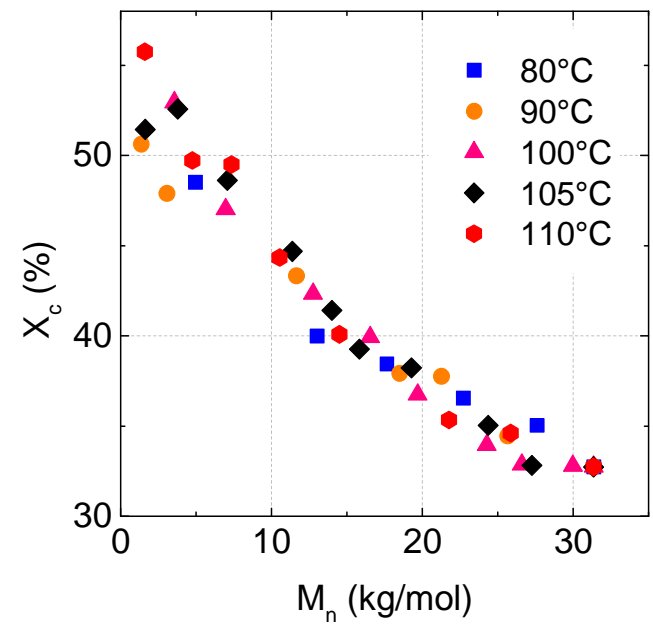

Figure 10: Changes in crystallinity ratio as a function of molar mass at different ageing temperatures

Results plotted in Figure 8 show that the evolution of the crystallinity ratio as a function of molar mass is independent of the ageing temperature. These results show that a master curve exists between $X_{c}$ and $M_{n}$ when ageing is performed above $T_{\mathrm{g}}$. This behaviour cannot be extrapolated for aging under $\mathrm{T}_{\mathrm{g}}$. In fact, due to low mobility chemicrystallization will probably not occur when the amorphous phase is in the glassy state.

\subsection{Identification of a critical molar mass $M_{c}^{\prime}$ based of the maximum stress criterion}

Tensile tests were then performed until failure for a wide range of ageing temperatures above $\mathrm{T}_{\mathrm{g}}$ and a wide range of ageing times (Figure 11). For each ageing temperature of interest here, a ductile-brittle transition was identified at a given ageing time. 


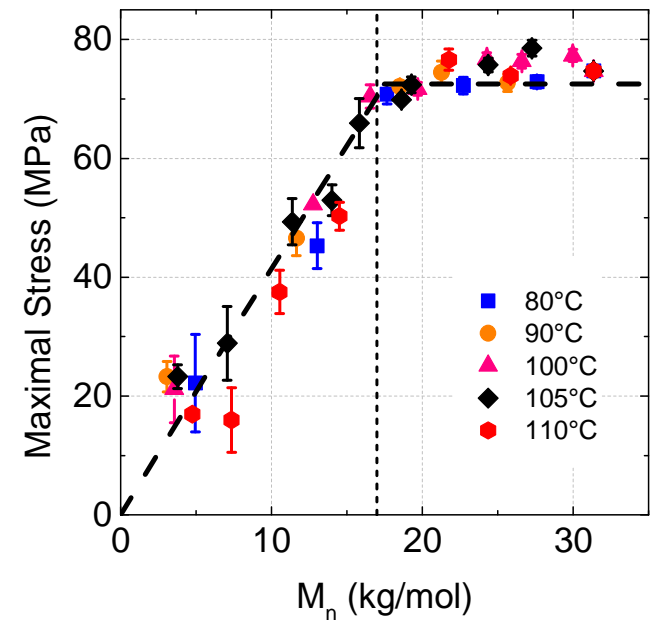

Figure 11 : Determination of critical molar mass based on the maximum stress criterion

Based on Figure 11, it is shown that the relationship between the maximal stress and $M_{n}$ is independent of the ageing temperature (within the temperature range considered here). When the molar mass is above $17 \mathrm{~kg} / \mathrm{mol}$, the maximum stress is constant for the temperatures of interest and the polymer exhibits a ductile behaviour. For $M_{n}$ values below $17 \mathrm{~kg} / \mathrm{mol}$, the maximum stress decreases and a brittle behaviour is observed for all the specimens studied here. The transition from ductile to brittle behaviour is related to a critical value of $M_{n}$ that is commonly named $\mathrm{M}_{\mathrm{c}}^{\prime}$. For PET, and in tensile conditions here, the $\mathrm{M}_{\mathrm{c}}^{\prime}$ is equal to $17 \mathrm{~kg} / \mathrm{mol}$; to the knowledge of the authors, this value has never been determined accurately during hydrolysis of PET. This value is compared with existing results from the literature for other polymers in Table 1.

For PET, some results can be found in the literature where brittle failures have been identified and coupled with $M_{n}$ values. In 1969, Stearne and Ward [29] worked with unaged PETs with different initial molar masses (27, $18.5,18,16.5$ and $11 \mathrm{~kg} / \mathrm{mol}$ ) and stated that brittle failures were identified on the specimens having an initial molar mass of $11 \mathrm{~kg} / \mathrm{mol}$. Their results represented a first step towards an identification of an $\mathrm{M}_{\mathrm{c}}^{\prime}$ value for PET between 16.5 and $11 \mathrm{~kg} / \mathrm{mol}$, however without taking into account hydrolysis degradation. In 1996, Wang et al [14] have worked on the degradation of PET using UV radiation and identified brittle failures at $M_{n}$ values below $11 \mathrm{~kg} / \mathrm{mol}$. Since then, we have not found any studies coupling brittles failures with $\mathbf{M}_{\mathrm{n}}$ values during hydrolysis. Finally, it is usually admitted that $\mathrm{M}_{\mathrm{c}}{ }_{\mathrm{c}}$ is proportional to $\mathrm{M}_{\mathrm{e}}$ with a factor from 5 to 10 [33]; For PET $\mathrm{M}_{\mathrm{e}}$ is equal to $1450 \mathrm{~g} / \mathrm{mol}$ [34] meaning that the proportionality factor here is around 10 .

Table $1: \mathrm{M}_{\mathrm{c}}^{\prime}$ values identified for various semi-crystalline polymers in the literature 


\begin{tabular}{cccccccc}
\hline Material & $\mathbf{M}_{\mathbf{c}} \mathbf{}^{(\mathbf{k g} / \mathbf{m o l})}$ & $\mathbf{X}_{\mathbf{c}}(\boldsymbol{\%})$ & $\mathbf{T}_{\text {aging }}\left({ }^{\mathbf{C}} \mathbf{C}\right)$ & Degradation & Specimen & Criteria & Reference \\
\hline PE & 25 & $42-50$ & $80-90$ & Oxidation & $\mathrm{H} 2, \mathrm{t}=70 \mu \mathrm{m}$ & $\sigma<\sigma_{0}$ & {$[\mathbf{3 4}]$} \\
PP & 35 & $/$ & 90 & Oxidation & $\mathrm{H} 2, \mathrm{t}=100 \mu \mathrm{m}$ & $/$ & {$[\mathbf{3 6}]$} \\
PTFE & 200 & $3-70$ & $/$ & Radiation & $\mathrm{H} 4, \mathrm{t}=1 \mathrm{~mm}$ & $\varepsilon=\varepsilon_{0} / 2$ & {$[\mathbf{3 7}]$} \\
PA11 & 13 & $/$ & $90-140$ & Hydrolysis & $\mathrm{t}=3 \mathrm{~mm}$ & $/$ & {$[\mathbf{3 8}]$} \\
PA11 & 10 & $20-30$ & $25-110$ & Oxidation & $\mathrm{t}=1 \mathrm{~mm}$ & $\varepsilon=\varepsilon_{0} / 2$ & {$[39]$} \\
\hline
\end{tabular}

Because secondary microplastics are subjected to very high degradation levels, it is important to consider the decrease of fracture properties when the polymer is brittle. A linear behaviour is observed between the maximal stress and $M_{n}$ when the PET is brittle. Here the stress at break decreases with $M_{n}$ and can be described using an empirical relationship, Eq.3:

$$
\sigma_{\max }=A+B \times M_{n}\left(\text { for } \mathrm{M}_{\mathrm{n}}<\mathrm{M}_{\mathrm{c}}\right)
$$

Where $\sigma_{\max }$ is the maximal stress in $\mathrm{MPa}, \mathrm{M}_{\mathrm{n}}$ is the molar mass in $\mathrm{kg} / \mathrm{mol}$, A and B are constants identified with experimental data. Here $\mathrm{A}$ is equal to $0.9 \mathrm{MPa}$ and $\mathrm{B}$ is equal to $3.7 \mathrm{MPa} / \mathrm{mol} / \mathrm{kg}$.

This means that using existing kinetic models for PET hydrolysis [21,22,33] coupled with the new relationship established here, we are able to predict the embrittlement time of PET during degradation as well as the decrease in fracture properties when the polymer exhibits a brittle behaviour. Although this relationship has been established under ageing conditions where the chemi-crystallization process occurs, this kind of prediction will provide the first step in understanding the formation and the behaviour of PET microplastics in the oceans.

However, the results presented here are based on ageing conditions above $\mathrm{T}_{\mathrm{g}}$, which induces chemi crystallization during ageing. This raises the following question: Can we identify a ductile-brittle transition of the PET during water ageing when ageing is performed below $\mathrm{T}_{\mathrm{g}}$, i.e. with no chemi-crystallization process? This is currently being studied by a series of lower temperature aging studies, but the kinetics are slow. The high water temperatures required to promote embrittlement in this material underline the need to integrate coupling with the other environmental factors, UV exposure and mechanical loading, into this study, in order to develop a general fragmentation prediction model. 


\section{Conclusion}

Two hundred micron thick films of PET have been aged in water at temperatures from $110^{\circ} \mathrm{C}$ to $80^{\circ} \mathrm{C}$, for up to 150 days. These were characterized in terms of molar mass, crystallinity ratio and tensile behaviour with the particularity of considering very high degrees of degradation.

When immersed in water at high temperature, PET undergoes hydrolysis that leads to chain scission in the amorphous phase and so a decrease of molar mass. In the meantime, because the ageing temperature is above $\mathrm{T}_{\mathrm{g}}$, an increase of crystallinity is observed during hydrolysis due to the chemi-crystallization process. These changes in the PET microstructure lead to a modification of the tensile properties of the polymer. When $\mathrm{M}_{\mathrm{n}}$ is above 17 $\mathrm{kg} / \mathrm{mol}$ a ductile behaviour is observed whereas when $\mathrm{M}_{\mathrm{n}}$ is below $17 \mathrm{~kg} / \mathrm{mol}$ a brittle behaviour is observed. In addition, the results clearly confirm that SEC measurement is a very useful experimental technique to characterize the degradation level of microplastics found in the oceans, provided that the unaged reference is known.

Moreover, for higher levels of degradation, i.e. the domain of interest when considering microplastic formation, the maximum stress at break decreases linearly with the molar mass and can be described using an empirical equation. This result provides a first step towards the understanding of how PET microplastic fragments form in the oceans. Work is underway to couple this with UV exposure and mechanical loading parameters.

\section{Acknowledgments}

The authors would like to thank the Microplastics project financed by Ifremer. The work of Christophe Peyronnet, Nicolas Lacotte, Mickael Premel Cabic, Luc Riou and Arnaud Le Moan is also gratefully acknowledged.

\section{References}

[1] Carpenter, E.J., Smith, K., (1972). Plastics on the Sargasso Sea surface. Science 175, 1240-1241

[2] Ivar do Sul, J.A., Costa, M.F. (2014). The present and future of microplastic pollution in the marine environment. Environmental Pollution, 185, 352-364. 
[3] Barnes D.K.A., Galgani F., Thompson R. C., Barlaz M., (2009) Environmental accumulation and fragmentation of plastic debris in global, Phil. Trans. R. Soc. B, 364 1985-1998

[4] Moore C. J., (2008) Synthetic polymers in the marine environment: a rapidly increasing, long-term threat Environ. Res., 108, 131-139

[5] Dehaut, A., Cassone, A. L., Frere, L., Hermabessiere, L., Himber, C., Rinnert, E., ... \& Duflos, G. (2016). Microplastics in seafood: benchmark protocol for their extraction and characterization. Environmental Pollution, $215,223-233$.

[6] Frère, L., Paul-Pont, I., Rinnert, E., Petton, S., Jaffré, J., Bihannic, I., ... \& Huvet, A. (2017). Influence of environmental and anthropogenic factors on the composition, concentration and spatial distribution of microplastics: a case study of the Bay of Brest (Brittany, France). Environmental pollution, 225, 211-222.

[7] Dümichen, E., Barthel, A. K., Braun, U., Bannick, C. G., Brand, K., Jekel, M., \& Senz, R. (2015). Analysis of polyethylene microplastics in environmental samples, using a thermal decomposition method. Water research, $85,451-457$.

[8] Elert, A. M., Becker, R., Duemichen, E., Eisentraut, P., Falkenhagen, J., Sturm, H., \& Braun, U. (2017). Comparison of different methods for MP detection: What can we learn from them, and why asking the right question before measurements matters?. Environmental Pollution, 231, 1256-1264.

[9] Andrady, A. L. (2017). The plastic in microplastics: a review. Marine pollution bulletin, 119(1), 12-22.

[10] Le Gac, P., Choqueuse, D., Melot, D., Melve, B., \& Meniconi, L. (2014). Lifetime prediction of polymer used as thermal insulation in offshore oil production conditions: Ageing on real structure and reliability of prediction. Polymer Testing, 34, 168-174.

[11] Le Saux, V., Le Gac, P. Y., Marco, Y., \& Calloch, S. (2014). Limits in the validity of Arrhenius predictions for field ageing of a silica filled polychloroprene in a marine environment. Polymer Degradation and Stability, $99,254-261$.

[12] E. Planes, B. Yrieix, C. Bas, L. Flandin, Chemical degradation of the encapsulation system in flexible PV panel as revealed by infrared and raman microscopies, Sol. Energy Mater. Sol. Cells 122 (0) (2014) 15-23.

[13] A. Goulas, K. Riganakos, M. Kontominas, Effect of ionizing radiation on physicochemical and mechanical properties of commercial multilayer coextruded flexible plastics packaging materials, Radiat. Phys. Chem. 68 (5) (2003) 865-872. 
[14] I. Ozen, G. Bozoklu, C. Dalgicdir, O. Yucel, E. Unsal, M. Cakmak, Y.Z. Menceloglu, Improvement in gas permeability of biaxially stretched $\{$ PET $\}$ films blended with high barrier polymers: the role of chemistry and processing conditions, Eur. Polym. J. 46 (2) (2010) 226-237

[15] Andrady, A. L. (2011). Microplastics in the marine environment. Marine pollution bulletin, 62(8), 15961605.

[16] McMahon, W., Birdsall, H. A., Johnson, G. R., \& Camilli, C. T. (1959). Degradation Studies of Polyethylene Terephthalate. Journal of Chemical and Engineering Data, 4(1), 57-79.

[18] Ioakeimidis, C., Fotopoulou, K. N., Karapanagioti, H. K., Geraga, M., Zeri, C., Papathanassiou, E., ... \& Papatheodorou, G. (2016). The degradation potential of PET bottles in the marine environment: An ATR-FTIR based approach. Scientific reports, 6, 23501.

[18] Wang, W., Taniguchi, A., Fukuhara, M., \& Okada, T. (1998). Surface nature of UV deterioration in properties of solid poly (ethylene terephthalate). Journal of Applied Polymer Science, 67(4), 705-714.

[19] Ballara, A., \& Verdu, J. (1989). Physical aspects of the hydrolysis of polyethylene terephthalate. Polymer Degradation and Stability, 26(4), 361-374.

[20] Dubelley, F., Planes, E., Bas, C., Pons, E., Yrieix, B., \& Flandin, L. (2017). The hygrothermal degradation of PET in laminated multilayer. European Polymer Journal, 87, 1-13

[21] Launay, A., Thominette, F., \& Verdu, J. (1994). Hydrolysis of poly (ethylene terephthalate): a kinetic study. Polymer Degradation and Stability, 46(3), 319-324.

[22] Campanelli, J. R., Kamal, M. R., \& Cooper, D. G. (1993). A kinetic study of the hydrolytic degradation of polyethylene terephthalate at high temperatures. Journal of applied polymer science, 48(3), 443-451.

[23] Kausch, H. H. (2012). Polymer fracture (Vol. 2). Springer Science \& Business Media.

[24] Laun, S., Pasch, H., Longiéras, N., \& Degoulet, C. (2008). Molar mass analysis of polyamides-11 and-12 by size exclusion chromatography in HFiP. Polymer, 49(21), 4502-4509.

[25] Van Krevelen, D. W., \& Te Nijenhuis, K. (2009). Properties of polymers: their correlation with chemical structure; their numerical estimation and prediction from additive group contributions. Elsevier.

[26] Dubelley, F., Planes, E., Bas, C., Pons, E., Yrieix, B., \& Flandin, L. (2017). Water Vapor Sorption Properties of Polyethylene Terephthalate over a Wide Range of Humidity and Temperature. The Journal of Physical Chemistry B, 121(8), 1953-1962

[27] Rabello, M. S., \& White, J. R. (1997). Crystallization and melting behaviour of photodegraded polypropylene-I. Chemi-crystallization. Polymer, 38(26), 6379-6387. 
[28] Lu, X. F., \& Hay, J. N. (2001). Isothermal crystallization kinetics and melting behaviour of poly (ethylene terephthalate). Polymer, 42(23), 9423-9431.

[29] Stearne, J. M., \& Ward, I. M. (1969). The tensile behaviour of polyethylene terephthalate. Journal of Materials Science, 4(12), 1088-1096.

[30] Golike, R. C., \& Lasoski Jr, S. W. (1960). Kinetics of hydrolysis of polyethylene terephthalate films. The Journal of Physical Chemistry, 64(7), 895-898.

[31] Davies, T., Goldsmith, P. L., Ravens, D. A. S., \& Ward, I. M. (1962). The kinetics of the hydrolysis of polyethylene terephthalate film. The Journal of Physical Chemistry, 66(1), 175-176.

[32] Elias, V., Salman, A., \& Goulias, D. (1998). The effect of pH, resin properties, and manufacturing process on laboratory degradation of polyester geosynthetics. Geosynthetics International, 5(5), 459-490

[33] Pickett, J. E., \& Coyle, D. J. (2013). Hydrolysis kinetics of condensation polymers under humidity aging conditions. Polymer degradation and stability, 98(7), 1311-1320.

[34] Fayolle, B., Colin, X., Audouin, L., \& Verdu, J. (2007). Mechanism of degradation induced embrittlement in polyethylene. Polymer Degradation and Stability, 92(2), 231-238.

[35] Fetters, L. J., Lohse, D. J., \& Colby, R. H. (2007). Chain dimensions and entanglement spacings. In Physical properties of polymers handbook (pp. 447-454). Springer, New York, NY.

[36] Fayolle, B., Audouin, L., \& Verdu, J. (2000). Oxidation induced embrittlement in polypropylene-a tensile testing study. Polymer Degradation and Stability, 70(3), 333-340.

[37] Fayolle, B., Audouin, L., \& Verdu, J. (2003). Radiation induced embrittlement of PTFE. Polymer, 44(9), 2773-2780.

[38] Jacques, B., Werth, M., Merdas, I., Thominette, F., \& Verdu, J. (2002). Hydrolytic ageing of polyamide 11. 1. Hydrolysis kinetics in water. Polymer, 43(24), 6439-6447.

[39] Okamba-Diogo, O., Richaud, E., Verdu, J., Fernagut, F., Guilment, J., \& Fayolle, B. (2016). Investigation of polyamide 11 embrittlement during oxidative degradation. Polymer, 82, 49-56. 